\title{
Radiative Forcing of Black Carbon over Delhi
}

\author{
Divya E. Surendran, Gufran Beig, Sachin D. Ghude, A. S. Panicker, \\ M. G. Manoj, Dilip. M. Chate, and Kaushar Ali
}

Indian Institute of Tropical Meteorology, Pune 411 008, India

Correspondence should be addressed to Gufran Beig; beig@tropmet.res.in

Received 15 February 2013; Revised 23 August 2013; Accepted 12 September 2013

Academic Editor: Margherita Premuda

Copyright (C) 2013 Divya E. Surendran et al. This is an open access article distributed under the Creative Commons Attribution License, which permits unrestricted use, distribution, and reproduction in any medium, provided the original work is properly cited.

\begin{abstract}
The radiative effects of black carbon (BC) aerosols over New Delhi, the capital city of India, for the period August 2010-July 2011, have been investigated using Santa Barbara DISTORT Atmospheric Radiative Transfer (SBDART) model in the present paper. The monthly mean BC concentrations in Delhi, an urban location, vary in between $15.935 \pm 2.06 \mu \mathrm{g} \mathrm{m}^{-3}$ (December 2010)-2.44 \pm $0.58 \mu \mathrm{g} \mathrm{m}^{-3}$ (July 2011). The highest value for monthly mean BC forcing has been found to be in November $2010\left(66.10 \pm 6.86 \mathrm{Wm}^{-2}\right)$ and the lowest in July $2011\left(23 \pm 3.89 \mathrm{Wm}^{-2}\right)$. Being the host city for the XIX Commonwealth Games (CWG-2010), government of Delhi set up a plan to reduce emissions of air pollutants during Games, from 03 October to 14 October, 2010. But opposite to the expectations, the emission controls implemented were not sufficient to reduce the pollutants like black carbon (BC), and therefore relatively a high value of $\mathrm{BC}$ radiative forcing $(44.36 \pm 2.4)$ was observed during the month of October 2010.
\end{abstract}

\section{Introduction}

Atmospheric aerosols play a major role in the earth climate because of their potential to perturb the radiation balance of the earth at regional and global scales. They influence the weather and climate directly by scattering and absorbing solar radiation [1] and indirectly by acting as cloud condensation nuclei, thereby affecting the droplet concentrations, optical properties, precipitation rate, and lifetime of clouds [2]. Among the absorbing aerosols, black carbon $(\mathrm{BC})$ is gaining considerable significance because it is a strong absorber of the solar radiation in the visible and near-infrared wavelengths and subsequently because of its ability to alter the radiation budget $[3,4]$. BC is the second strongest contributor to global warming next to carbon dioxide [5]. BC is produced as primary particles from incomplete combustion processes such as fossil fuel and biomass burning, and hence most of the BC in the atmosphere originates from human-made activities. $\mathrm{BC}$ emissions have varied in response to changes in fossil fuel usage and technology development, and the estimated fossil fuel $\mathrm{BC}$ emissions are the highest in developing countries, especially China and India [6].

Highly industrialized cities in the world face major threats from air pollution. New Delhi, the capital city of India, is also no exception to this, and since it is located in the IndoGangetic Plains (IGP), a significant part of the pollutants over there are of absorbing type. Rapid urbanization and industrialization has brought up growingly large number of vehicles, factories, as well as power plants in Delhi and surrounding areas during the last two decades [7]. As a result, Delhi has evidenced serious air pollution problem [8-11]. Significant portion of the population in Delhi is regularly exposed to unhealthy levels $[8,11,12]$ of pollution which is a cause of concern. The significant impact of particulate matters on the pollution over Delhi has been reported in $[12,13]$. It may be noted that total number of vehicles in the city had reached about 5.73 million by the year 2010 [14]. Increased level of pollution in the Delhi region was a cause of immense concern to the Commonwealth Games 2010 Organizing Committee as well as to the government of India and the Delhi government, and there was a real need of improvement in the air quality of the Delhi region for successful organization of the games during OctoberNovember 2010.

Delhi hosted the XIX Commonwealth Games (CWG2010), for the first time in India, and it lasted from 03 October to 14 October, 2010. As an initiative, the government of Delhi executed an ambitious air quality monitoring program to 
reduce the emissions of air pollutants and also to monitor the different pollutant levels before and during the games period. The aim of these restrictions was to improve the air quality through control measures, which has shown some success in the past during large international sporting events in polluted cities like Beijing $[15,16]$. Under this initiative the "System for Air quality Forecasting And Research" (SAFAR) was an intensive experiment initiated by the Ministry of Earth Sciences (MoES), government of India, for investigating the air quality in Delhi during the CWG period and evaluating the effectiveness of the air pollution control measures. The SAFAR program for CWG-2010 provided a unique opportunity not only to examine ambient air quality during games but also to assess the air quality of Delhi as a whole.

In the present study, we investigate the radiative effect of BC aerosols during the year 2010-2011, in which the CWG event had taken place. The geographical features of the study location are presented in Section 2, and data and methodology are given in Section 3. The results and discussions are provided in Section 4, and the summary and inferences are rendered in Section 5.

\section{Study Location: Site Description and Meteorology}

New Delhi, the capital region of India, situated in the northern part of the country, is located between the latitudes of $28^{\circ} 24^{\prime}$ and $28^{\circ} 53^{\prime}$ North and $76^{\circ} 50^{\prime}$ and $77^{\circ} 20^{\prime}$ East. It stretches over an area of 1483 square kilometers. The population of Delhi according to the 2011 census stands at about 16 million, making it the 18th most populated state in India [17]. The Thar and Margo Deserts in the western India are very close to the location of Delhi. So this city is faced with a typical problem of desert aerosols every year during the premonsoon period, that is, April-June. These aerosols are brought by windblown dusts from the Thar Desert in Rajasthan. The total suspended particulate matter (TSP) concentration during this period goes enormously high. Consequently, the visibility is reduced and the local radiative forcing is significantly affected. The summers in Delhi are very hot and winters are very cold. The temperature ranges from $45^{\circ} \mathrm{C}$ in the summer to $3^{\circ} \mathrm{C}$ in the winter. The rainy season is from July to September with average annual rainfall of $\sim 670 \mathrm{~mm}$. Well before the commencement of the commonwealth games, Delhi was in the grip of heavy monsoonal rain. Cloudy sky condition persisted for a prolonged duration until a week before the games when monsoon withdrawal began in Delhi. The Delhi region was completely devoid of monsoonal/rainfall activity during the games period.

\section{Measurements and Methodology}

3.1. Black Carbon Mass Concentration Measurements. A network of air quality monitoring system (AQMS) had been set up in Delhi. More details on the Delhi SAFAR network and air quality and weather monitoring setups used can be found at http://safar.tropmet.res.in/. Black carbon mass concentration measurements were made using seven wavelengths (370, $470,520,590,660,880$, and $950 \mathrm{~nm})$ AE31 Aethalometer (Magee Scientific, USA). The aethalometer measures BC mass concentrations from the attenuation of a beam of light transmitted through the sample collected on a filter, which is proportional to the amount of $\mathrm{BC}$ mass loading in the filter deposit [18]. This attenuation absorption coefficient is then converted into $\mathrm{BC}$ mass concentration. The conversion of attenuation absorption coefficient into BC mass concentration is done using appropriate absorption efficiency, which varies as a function of wavelength. Absorption coefficients of aerosols as a function of wavelength are calculated $[19,20]$ as follows:

$$
\beta_{\mathrm{abs}}(\lambda)=\frac{-1}{C R} \frac{A \ln \left(i_{2} / i_{1}\right)}{\mathrm{Q} \Delta t},
$$

where $i_{1}$ and $i_{2}$ are the intensities of the sample and the reference beams, respectively, after a sampling time interval $(\Delta t), Q$ is the volume of air sampled during the time interval $\Delta t$, and $A$ is the area of the exposed spot on the filter where aerosols are collected. Coefficient $C$ is the correction factor applied to account for any change in the absorption occurring due to aerosols on the filter over that of the airborne particles. Coefficient $R$ is an empirical correction factor and describes the change in the aethalometer response with increased particle loading on the filter. The value obtained for $\beta_{\text {abs }}(\lambda)$ is divided by a mass absorption coefficient, $\sigma_{\text {abs }}(\lambda)$ (in units of $\mathrm{m}^{2} \mathrm{~g}^{-1}$ ), to obtain the mass concentration $M_{\mathrm{BC}}(\lambda)$ in $\mu \mathrm{g} \mathrm{m}^{-3}$ [21]

$$
M_{\mathrm{BC}}(\lambda)=\frac{\beta_{\mathrm{abs}}(\lambda)}{\sigma_{\mathrm{abs}}(\lambda)}=\frac{\beta_{\mathrm{abs}}(\lambda) C}{\sigma_{\mathrm{atn}}(\lambda)},
$$

where $\sigma_{\text {abs }}(\lambda)$ and $\sigma_{\text {atn }}(\lambda)=\sigma_{\text {abs }}(\lambda) C$ are the mass specific absorption and attenuation cross sections, respectively. The method is described in detail by [22]. The hourly averaged data of BC compiled for a period from 20 August 2010 to 31 July 2011 were analyzed in this paper.

\subsection{Estimation of $B C$ Radiative Forcing}

3.2.1. Necessary Inputs: Aerosol Optical Properties. The clear sky total (direct + diffuse) aerosol radiative forcing at the surface and top of the atmosphere was calculated in the shortwave $(0.2-4.0 \mu \mathrm{m})$ region using the SBDART model, developed by Ricchiazzi et al. [23]. SBDART computes plane parallel radiative transfer in clear sky conditions within the earth atmosphere and at the surface. The model is well suited to study the radiation budget of the earth atmosphere system. The primary input parameters required for calculating aerosol radiative forcing are aerosol optical depth (AOD), single scattering albedo (SSA), and the asymmetry parameter (ASP). BC mass fractions were used as input in the Optical Properties of Aerosols and Clouds (OPAC) model developed by Hess et al. [22] to derive spectral aerosol optical parameters such as aerosol optical depth (AOD), single scattering albedo (SSA), and asymmetry parameter (ASP) at different relative humidity conditions over Delhi. Subsequently BC mass fractions alone were used in OPAC to 


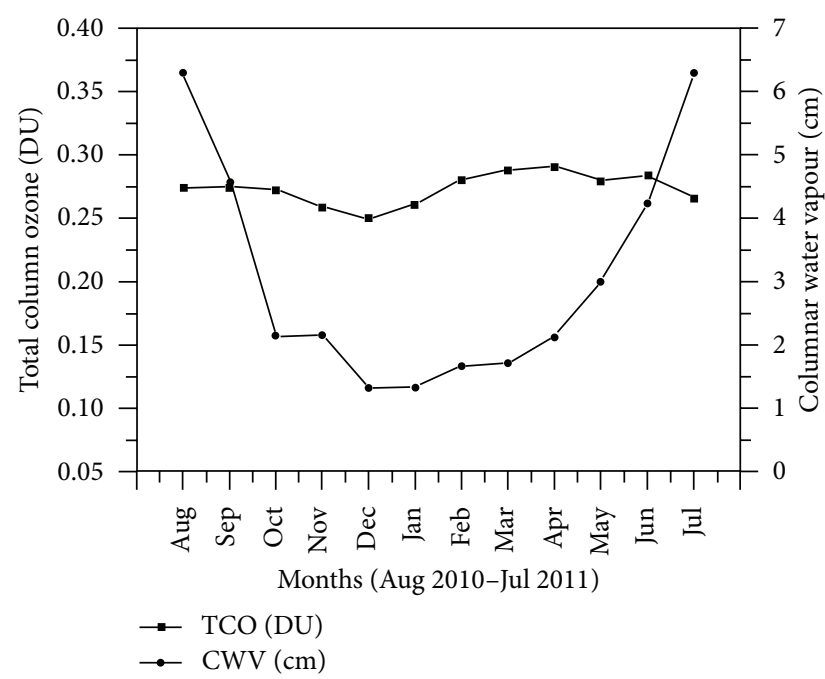

FIgURE 1: Monthly mean variation of total column ozone and column water vapour.

derive spectral aerosol properties solely for $\mathrm{BC}$ component as explained in [24]. We used the standard urban model, as the observational site experiences similar to environmental conditions during observational periods. The values of SSA and ASP for the $550 \mathrm{~nm}$ wavelength are 0.208 and 0.353 .

3.2.2. Additional Inputs: Atmosphere, Ozone, Water Vapor, and Surface Reflectance. In addition to aerosol properties, atmospheric profiles of temperature, pressure, columnar ozone, and water vapor are necessary for the aerosol radiative forcing. As no vertical profiling data of aerosol and meteorological parameters were available over the site, we used the standard midlatitude atmospheric model of temperature and humidity [25] in SBDART model in both the cases (for "with BC" analysis and for "without BC" case) for this study. Aerosol vertical distribution is constrained from the McClatchey et al. [25] models of vertical aerosol profiles for visibility 5 and $23 \mathrm{~km}$, for the average visibility conditions prevailed over the site as described by [23]. The vertical profiles for visibility 5 and $23 \mathrm{~km}$ follow exponential profiles with density scale heights of 0.99 and $1.45 \mathrm{~km}$, respectively. A weighted average of these vertical distributions is used when an intermediate value of visibility is selected. The standard sand albedo model defined in SBDART [23] has been used to constrain surface reflectance. The monthly mean total column ozone (TCO) and precipitable water content (PWC) over Delhi as obtained from Ozone Monitoring Instrument (OMI) have been used for the estimation of $\mathrm{BC}$ radiative forcing using a one-dimensional radiative transfer Santa Barbara Discrete ordinate Atmospheric Radiative Transfer (SBDART) model. Columnar ozone shows a winter low and a summer high, consistent with the seasonal variation over tropics (Figure 1). Columnar water vapour in Delhi is showing a maximum during the summer months of AugustSeptember (2010) and June-July (2011) (Figure 1). In order to analyze the stability of atmosphere with regard to the $\mathrm{BC}$

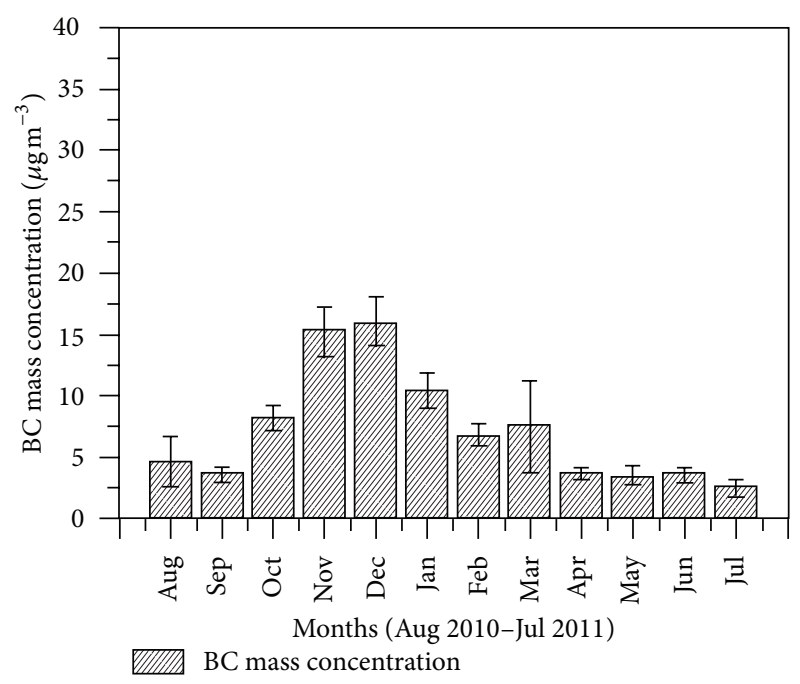

FIGURE 2: Monthly mean variation of BC mass concentration during August 2010-July 2011 over Delhi.

loading, we have used the atmospheric sounding data from the URL: http://weather.uwyo.edu/upperair/sounding.html.

3.3. Radiative Forcing Calculation. BC Radiative Forcing has been calculated for four individual days in a month for "with $\mathrm{BC}$ " condition and "without $\mathrm{BC}$ " condition and monthly average $\mathrm{BC}$ forcing has been taken for each month. We used the methodology explained in [24] to estimate the $\mathrm{BC}$ radiative forcing. Direct $\mathrm{BC}$ radiative forcing $(\mathrm{RF})$ is defined as the difference in net fluxes at the surface, bottom of atmosphere (BOA), or at the top of atmosphere (TOA), with and without $\mathrm{BC}$. The RF is given by the expression:

$$
(\mathrm{RF})_{\mathrm{BOA}, \mathrm{TOA}}=\left[F_{\mathrm{BC}}-F_{\mathrm{NoBC}}\right]_{\mathrm{BOA}, \mathrm{TOA}} \text {, }
$$

where

$$
F_{\mathrm{BC}, \mathrm{NoBC}}=(F \downarrow-F \uparrow)_{\mathrm{BC}, \mathrm{NoBC}} \cdot
$$

The difference between the radiative forcing at the top of the atmosphere and the surface is designated as the atmospheric forcing and is written as

$$
(\mathrm{RF})_{\mathrm{ATM}}=(\mathrm{RF})_{\mathrm{TOA}}-(\mathrm{RF})_{\mathrm{BOA}} \text {, }
$$

where the subscript ATM represents the energy trapped within the atmosphere due to the presence of black carbon. If the $(R F)_{A T M}$ is positive, the $B C$ produces a net gain of radiative flux leading to heating, while a negative $(R F)_{A T M}$ indicates a net loss and thereby cooling.

The absorption and emission processes in the long wave at different altitudes in the atmosphere, when integrated over all the wavelengths, can result in either a net gain (warming) or loss (cooling) of radiative energy [26], while solar radiation always warms the atmosphere (5). The amount of energy trapped in the atmosphere, $(\mathrm{RF})_{\mathrm{ATM}}$, due to $\mathrm{BC}$ 

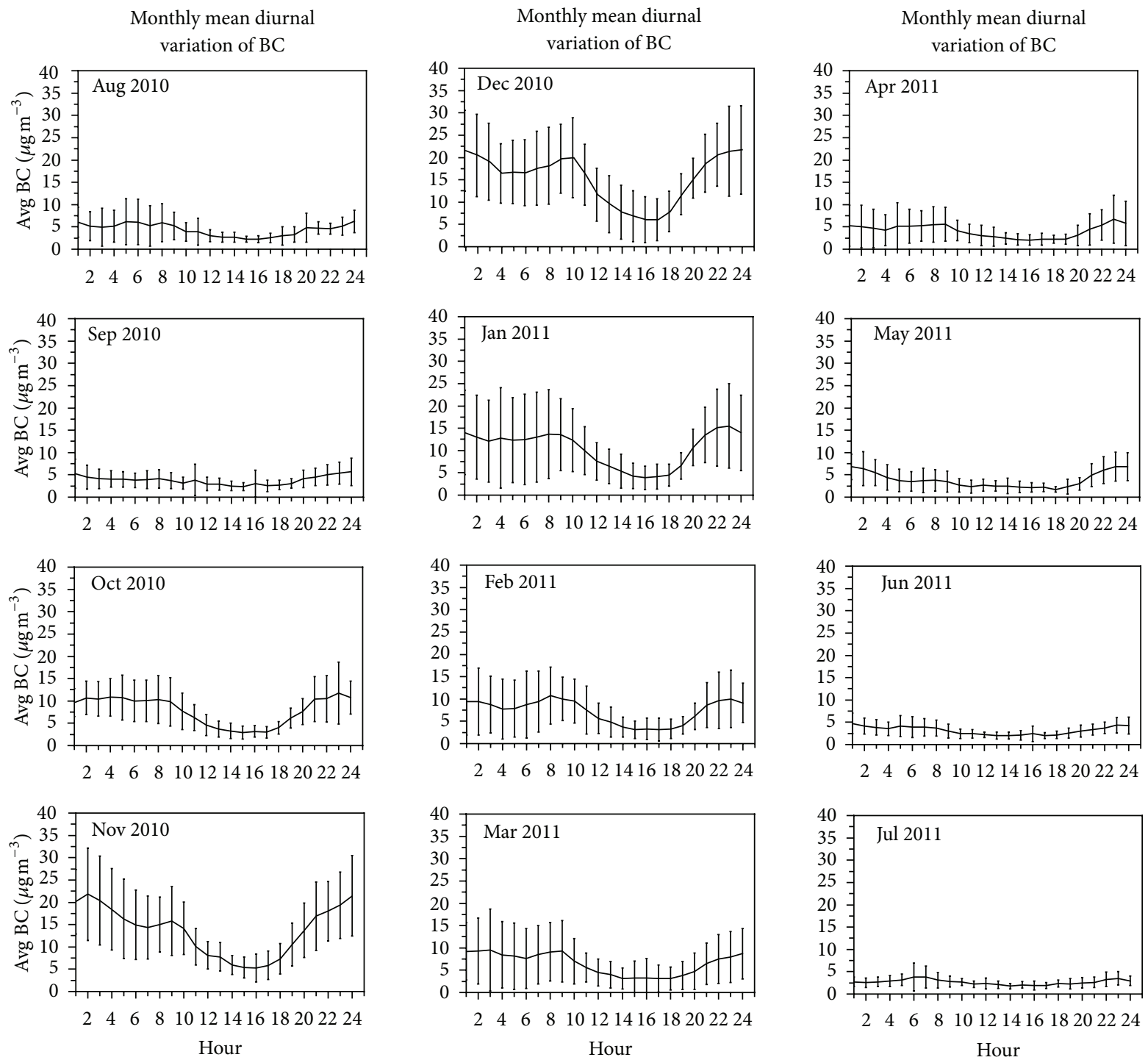

FIGURE 3: Monthly mean diurnal variation of BC mass concentration during August 2010-July 2011 over Delhi.

in the shortwave region, gets converted into heat. The solar heating rate can be calculated as

$$
\frac{\partial T}{\partial t}=\frac{-1}{\rho C_{p}} \frac{(\mathrm{RF})_{\mathrm{ATM}}}{\Delta z},
$$

where $\partial T / \partial t$ is the heating rate (K/day), $\rho$ is the density, and $C_{p}$ is the specific heat capacity of air at constant pressure [27].

\section{Results and Discussions}

4.1. Seasonal and Diurnal Variation of BC. BC aerosol mass concentrations measured for $24 \mathrm{hrs}$ per day during each month are averaged and the monthly mean BC mass concentrations are obtained. Figure 2 shows the monthly mean variation of the BC aerosols. Vertical bars denote the standard deviation from the mean, which indicate the variability in the $\mathrm{BC}$ mass concentration measured during that month. BC mass concentrations in Delhi exhibit a strong seasonal cycle marked by a winter high and a summer low. The monthly mean BC concentrations vary between $15.935 \pm 2.063 \mu \mathrm{g} \mathrm{m}^{-3}$ (December 2010) and $-2.445 \pm 0.58 \mu \mathrm{g} \mathrm{m}^{-3}$ (July 2011). During winter the boundary layer is shallow and holds the pollutants in a smaller volume near the earth surface when compared to summer.

BC exhibited a distinct diurnal variation with the highest concentration occurring $0600 \mathrm{~h}$ to $0900 \mathrm{~h}$ and again at around $2000 \mathrm{~h}$ till midnight and low concentration from $\sim 1000 \mathrm{~h}$ to $1700 \mathrm{~h}$ (Figure 3 ). The diurnal pattern is mainly due to the changes in the mixing heights. In the morning, after the sunrise, the nocturnal boundary layer brakes, lifting up the particles, especially those in fine size. This gave a sharp peak in the morning. After that, the concentrations went on decreasing gradually due to increased convective activity and the minimum value reached at about $16 \mathrm{~h}$; afterwards concentrations started building up slowly again due to the decadence of the local boundary layer and the second peak 


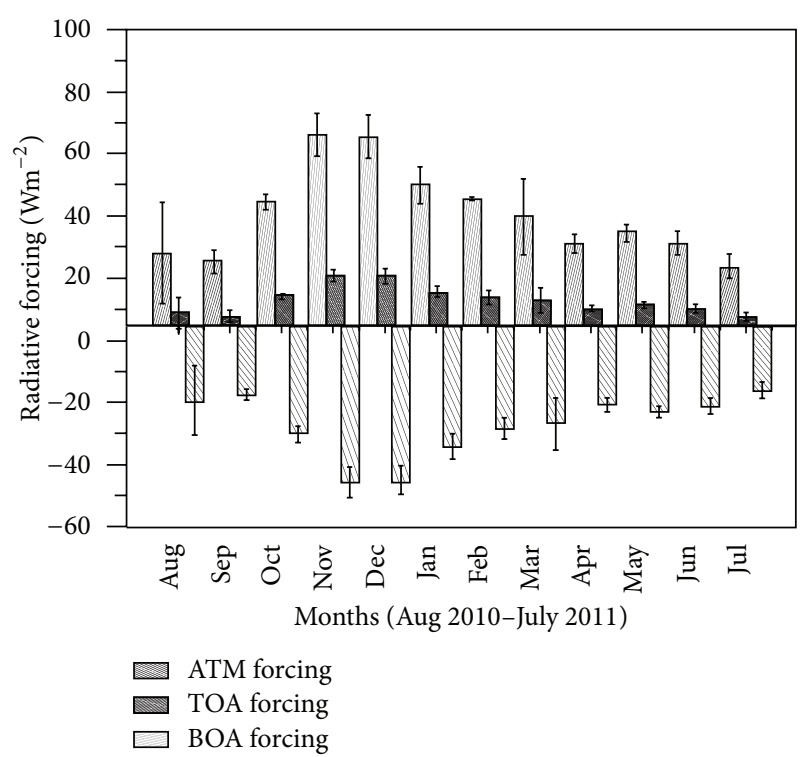

FIgURE 4: Variation of monthly averages of clear sky BC radiative forcing over TOA, BOA and in the atmosphere from August 2010 to July 2011.

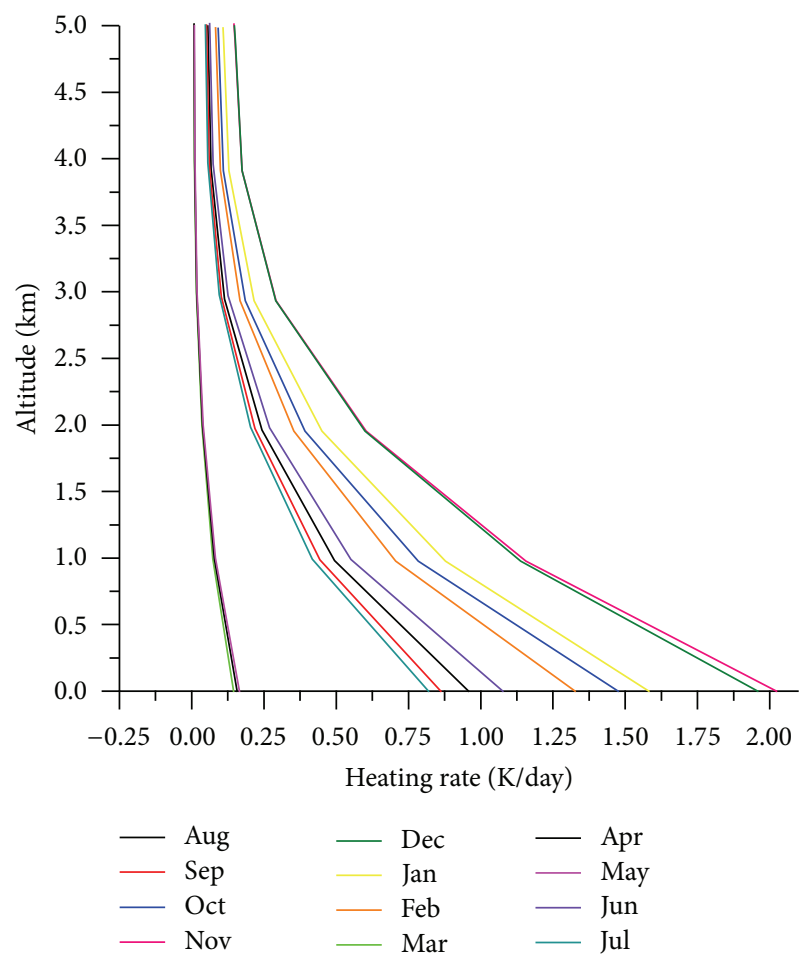

FIGURE 5: BC heating rates as a function of altitude for each month from August 2010 to July 2011.

was observed in the evening. Similar variations depending upon the changes in local boundary layer have been reported by [28-30].

Apart from these local boundary layer variations, the effect of traffic intensity is also a crucial factor as vehicular emissions are one of the major sources for BC aerosols [24].
This diurnal feature is observed in all the seasons, but with varying degrees of magnitude of the peaks (highest in winter and lowest in monsoon).

4.2. BC Radiative Forcing. It has been observed that the monthly mean $\mathrm{BC}$ forcing is the highest in the month of November $\left(66 \pm 6.86 \mathrm{Wm}^{-2}\right)$ and December $(65.43 \pm$ $6.9 \mathrm{Wm}^{-2}$ ). The forcing solely due to $\mathrm{BC}$ during winter was found to be $-45.31 \mathrm{Wm}^{-2}$ at the surface and $+20.45 \mathrm{Wm}^{-2}$ at TOA, indicating strong radiative absorption by BC. Figure 4 shows the average variation in $\mathrm{BC}$ radiative forcing obtained over Delhi at the surface, top of the atmosphere (TOA), and in the atmosphere every month. The lowest forcing is found to be in the month of July $\left(23 \pm 3.89 \mathrm{Wm}^{-2}\right)$. This could be due to that, in normal conditions, the amount of atmospheric aerosols is the minimum during the monsoon months (JJAS), because of the scavenging due to wet removal processes. Figure 5 shows the monthly mean shortwave heating rates obtained over Delhi during the period August 2010-July 2011.

Even though there is a strict imposed restriction setup by the Delhi government during the CWG period, there is considerable amount of $\mathrm{BC}$ loading into the atmosphere; therefore a relatively high radiative forcing $(44.36 \pm 2.4)$ was observed during the month of October 2010. During the games, the high value of $\mathrm{BC}$ concentration and high radiative forcing suggest that control action taken to reduce pollution during games did not have the desired policy-induced effect to reduce pollution levels below the air quality guidelines.

4.3. BC Radiative Forcing in relation to Atmospheric Stability. The accumulation of aerosols in the atmosphere depends on the stability of the atmosphere. A stable atmosphere traps pollutant and hence there will be large pollutants and large forcing. We examine the static stability of the lower atmosphere by determining the change in potential temperature $(\theta)$, with respect to the height $(z)$, for three periods (pre-, during, and post-CWG). Stability conditions of the atmosphere in terms of potential temperature are given as

$$
\text { If }\left|\begin{array}{l}
\frac{d \theta}{d z}>0 \\
\text { Stable }
\end{array}\right| ; \quad\left|\begin{array}{l}
\frac{d \theta}{d z}<0 \\
\text { Unstable }
\end{array}\right| ; \quad\left|\begin{array}{l}
\frac{d \theta}{d z}=0 \\
\text { Neutral }
\end{array}\right| .
$$

During the month of October, it has been observed that the condition of the lower atmosphere is relatively stable (Figure 6), which is favourable for less dispersion and enhanced trapping of particles in the boundary layer. In spite of having heavy traffic restrictions, the high $\mathrm{BC}$ values in October during CWG compared to pre-post-CWG periods are associated with the highly stable atmosphere, which traps the pollutants, indicated by positive potential temperature values.

\section{Summary and Conclusions}

$\mathrm{BC}$ radiative forcing is high during the month of November 2010 and it is very low during the month of July 2011. It 


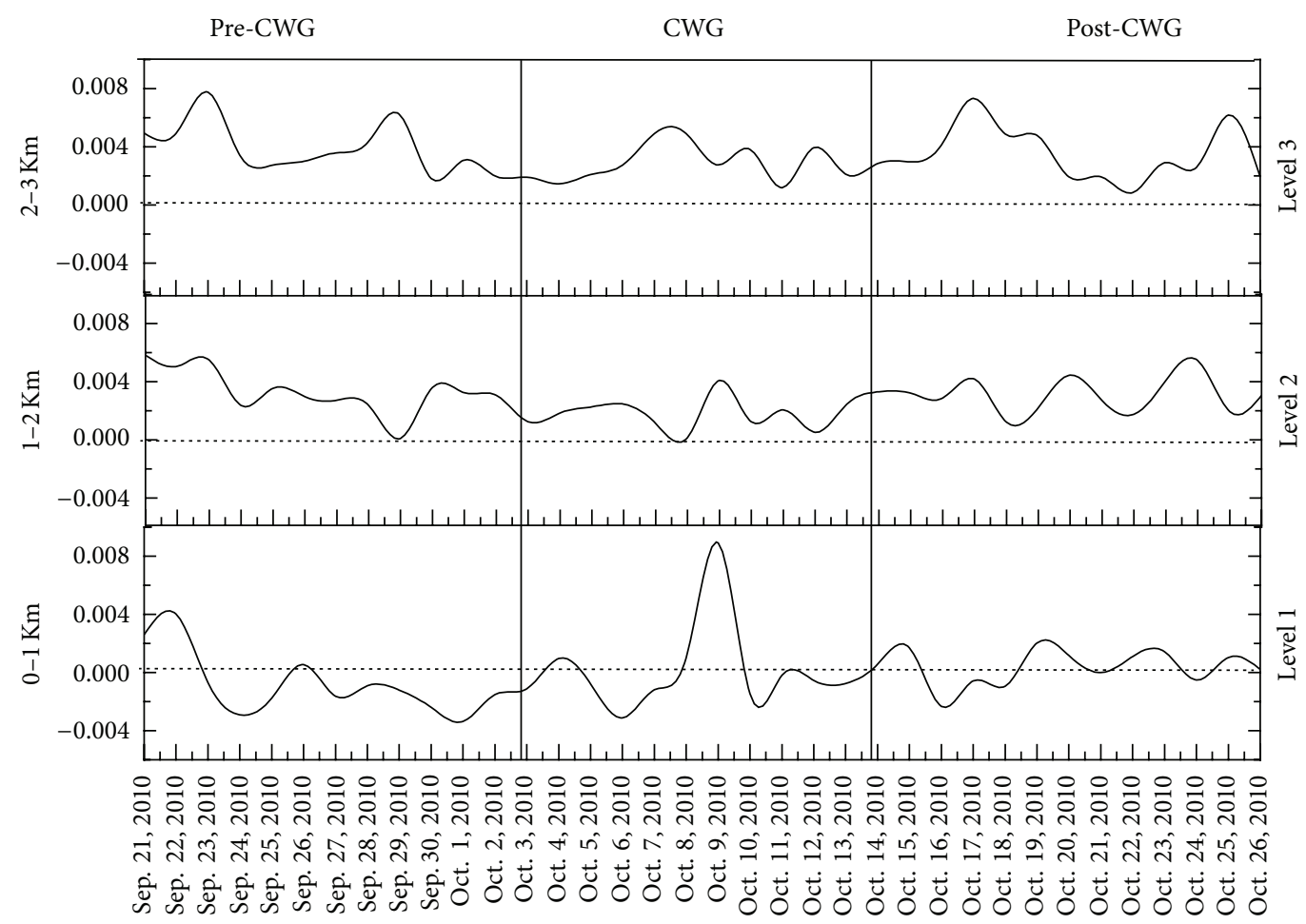

FIGURE 6: Change in potential temperature with respect to the altitude for the 3 periods (pre, during, and post-CWG).

was expected that the imposed restriction on the traffic, construction activities, and the functioning of thermal power plants would result in reduction of $\mathrm{BC}$ and other pollutants, ensuring an improvement in air quality during the international games event. However, the observations and radiative forcing calculations indicate that this expected result was not achieved, with higher pollution and radiative forcing during the games period. This result reveals that pollution reductions measures for CWG-2010 were not sufficient to eliminate BC and other pollutants to ensure good air quality. A speculation based on the present study is made that further increase in the industrial and the vehicular activities in Delhi and surrounding areas may cause emission of BC aerosols and production of secondary pollutants to an extent which may deteriorate the air quality extremely in Delhi and in turn may enhance the radiative forcing effect, which will remain as ancontrollable serious threat to the plantation and human health in future. Therefore, more relevant and cautious steps need to be taken to reduce the pollutants' emissions to significantly improve the air quality in Delhi and the surrounding regions.

\section{Acknowledgments}

The authors would like to thank the System of Air quality Forecasting and Research (SAFAR) project and Ministry of Earth Sciences (MOES) for financial support. Divya E. Surendran gratefully acknowledges Dr. S. Dipu for providing the suitable technical support.

\section{References}

[1] R. J. Charlson, S. E. Schwartz, J. M. Hales et al., "Climate forcing by anthropogenic aerosols," Science, vol. 255, no. 5043, pp. 423430, 1992.

[2] D. Rosenfeld, "Suppression of rain and snow by urban and industrial air pollution," Science, vol. 287 , no. 5459 , pp. $1793-$ 1796, 2000.

[3] J. M. Haywood and V. Ramaswamy, "Global sensitivity studies of the direct radiative forcing due to anthropogenic sulfate and black carbon aerosols," Journal of Geophysical Research D, vol. 103, no. 6, pp. 6043-6058, 1998.

[4] M. Z. Jacobson, "Global direct radiative forcing due to multicomponent anthropogenic and natural aerosols," Journal of Geophysical Research D, vol. 106, no. 2, pp. 1551-1568, 2001.

[5] V. Ramanathan and G. Carmichael, "Global and regional climate changes due to black carbon," Nature Geoscience, vol. 1, no. 4, pp. 221-227, 2008.

[6] T. Novakov, V. Ramanathan, J. E. Hansen et al., "Large historical changes of fossil-fuel black carbon aerosols," Geophysical Research Letters, vol. 30, no. 6, p. 1324, 2003.

[7] P. S. Kulkarni, S. D. Ghude, and D. Bortoli, "Tropospheric ozone (TOR) trend over three major inland Indian cities: Delhi, Hyderabad and Bangalore," Annales Geophysicae, vol. 28, no. 10, pp. 1879-1885, 2010.

[8] S. L. Jain, B. C. Arya, A. Kumar, S. D. Ghude, and P. S. Kulkarni, "Observational study of surface ozone at New Delhi, India," International Journal of Remote Sensing, vol. 26, no. 16, pp. 35153524, 2005.

[9] N. Badhwar, R. C. Trivedi, B. Sengupta et al., "Air quality status and trends in India," in Proceedings of the Better Air Quality 
Workshop, Clean Air Initiative for Asian Cities, Yogyakarta, Indonesia, 2006.

[10] B. R. Gurjar, J. A. Van Aardenne, J. Lelieveld, and M. Mohan, "Emission estimates and trends (1990-2000) for megacity Delhi and implications," Atmospheric Environment, vol. 38, no. 33, pp. 5663-5681, 2004.

[11] S. D. Ghude, S. L. Jain, B. C. Arya et al., "Ozone in ambient air at a tropical megacity, Delhi: characteristics, trends and cumulative ozone exposure indices," Journal of Atmospheric Chemistry, vol. 60, no. 3, pp. 237-252, 2008.

[12] M. Sharma, R. Pandey, M. Maheshwary et al., "Air quality index and its interpretation for the city of Delhi. Clean Air," International Journal on Energy for a Clean Environment, vol. 4, pp. 83-98, 2003.

[13] P. K. Gupta, Khem Singh, C. K. Dixit et al., "Spatial distribution in aerosol mass and size characteristics between Delhi and Hyderabad during land campaign in February 2004," Indian Journal of Radio \& Space Physics, vol. 36, no. 4, 2007.

[14] S. K. Sahu, G. Beig, and N. S. Parkhi, "Emissions inventory of anthropogenic $\mathrm{PM}_{2.5}$ and $\mathrm{PM}_{10}$ in Delhi during commonwealth games 2010," Atmospheric Environment, vol. 45, no. 34, pp. 61806190, 2011.

[15] C. C.-K. Chou, C.-Y. Tsai, C.-C. Chang, P.-H. Lin, S. C. Liu, and T. Zhu, "Photochemical production of ozone in Beijing during the 2008 olympic games," Atmospheric Chemistry and Physics, vol. 11, no. 18, pp. 9825-9837, 2011.

[16] Y. Wang, J. Hao, M. B. McElroy et al., "Ozone air quality during the 2008 Beijing olympics: effectiveness of emission restrictions," Atmospheric Chemistry and Physics, vol. 9, no. 14, pp. 5237-5251, 2009.

[17] Census of India, 2011, http://www.censusindia.gov.in/2011-provresults/prov_results_paperl_india.html.

[18] A. D. A. Hansen and T. Novakov, "Real-time measurement of aerosol black carbon during the carbonaceous species methods comparison study," Aerosol Science and Technology, vol. 12, no. 1, pp. 194-199, 1990.

[19] B. A. Bodhaine, "Aerosol absorption measurements at barrow, mauna loa and the south pole," Journal of Geophysical Research, vol. 100, no. 5, pp. 8967-8975, 1995.

[20] E. Weingartner, H. Saathoff, M. Schnaiter, N. Streit, B. Bitnar, and U. Baltensperger, "Absorption of light by soot particles: determination of the absorption coefficient by means of aethalometers," Journal of Aerosol Science, vol. 34, no. 10, pp. 1445-1463, 2003.

[21] A. D. A. Hansen, H. Rosen, and T. Novakov, "The aethalometer-an instrument for the real-time measurement of optical absorption by aerosol particles," Science of the Total Environment, vol. 36, pp. 191-196, 1984.

[22] M. Hess, P. Koepke, and I. Schult, "Optical properties of aerosols and clouds: the software package OPAC," Bulletin of the American Meteorological Society, vol. 79, no. 5, pp. 831-844, 1998.

[23] P. Ricchiazzi, S. Yang, C. Gautier, and D. Sowle, "SBDART: a research and teaching software tool for plane-parallel radiative transfer in the earth's atmosphere," Bulletin of the American Meteorological Society, vol. 79, no. 10, pp. 2101-2114, 1998.

[24] A. S. Panicker, G. Pandithurai, P. D. Safai, S. Dipu, and D.-I. Lee, "On the contribution of black carbon to the composite aerosol radiative forcing over an urban environment," Atmospheric Environment, vol. 44, no. 25, pp. 3066-3070, 2010.
[25] R. A. McClatchey, R. E. Fenn, J. E. A. Salby, F. E. Volz, and J. S. Garing, Optical Properties of the Atmosphere, Environmental research papers, Air Force Cambridge Research Laboratories, Cambridge, Mass, 3rd edition, 1972.

[26] S. Singh, S. Nath, R. Kohli, and R. Singh, "Aerosols over Delhi during pre-monsoon months: characteristics and effects on surface radiation forcing," Geophysical Research Letters, vol. 32, no. 13, pp. 1-4, 2005.

[27] S. Piao, V. Ramaswamy, D. Randall et al., "Infrared radiation," in Encyclopedia of Global Environmental Change, vol. 1, pp. 470475, 2002.

[28] K. N. Liou, An Introduction to Atmospheric Radiation, Academic Press, San Diego, Calif, USA, 1980.

[29] P. D. Safai, S. Kewat, P. S. Praveen et al., "Seasonal variation of black carbon aerosols over a tropical urban city of Pune, India," Atmospheric Environment, vol. 41, no. 13, pp. 2699-2709, 2007.

[30] S. N. Tripathi, S. Dey, V. Tare, S. K. Satheesh, S. Lal, and S. Venkataramani, "Enhanced layer of black carbon in a north Indian industrial city," Geophysical Research Letters, vol. 32, no. 12, pp. 1-4, 2005. 

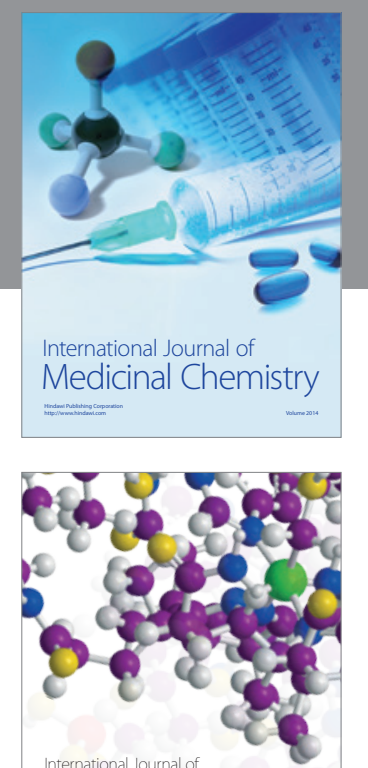

\section{Carbohydrate} Chemistry

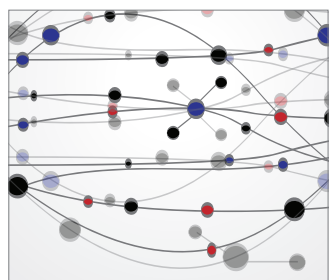

The Scientific World Journal
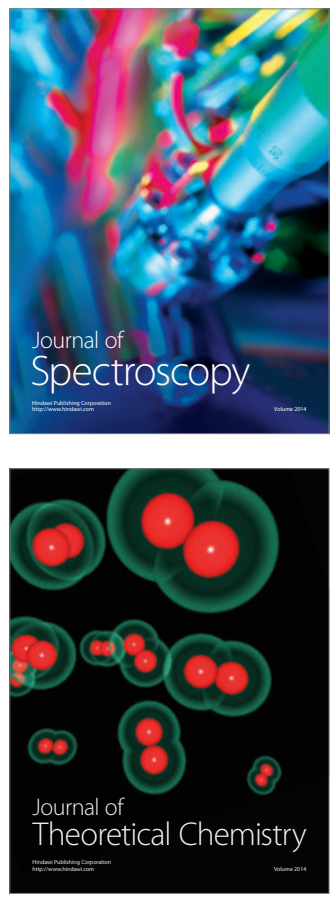
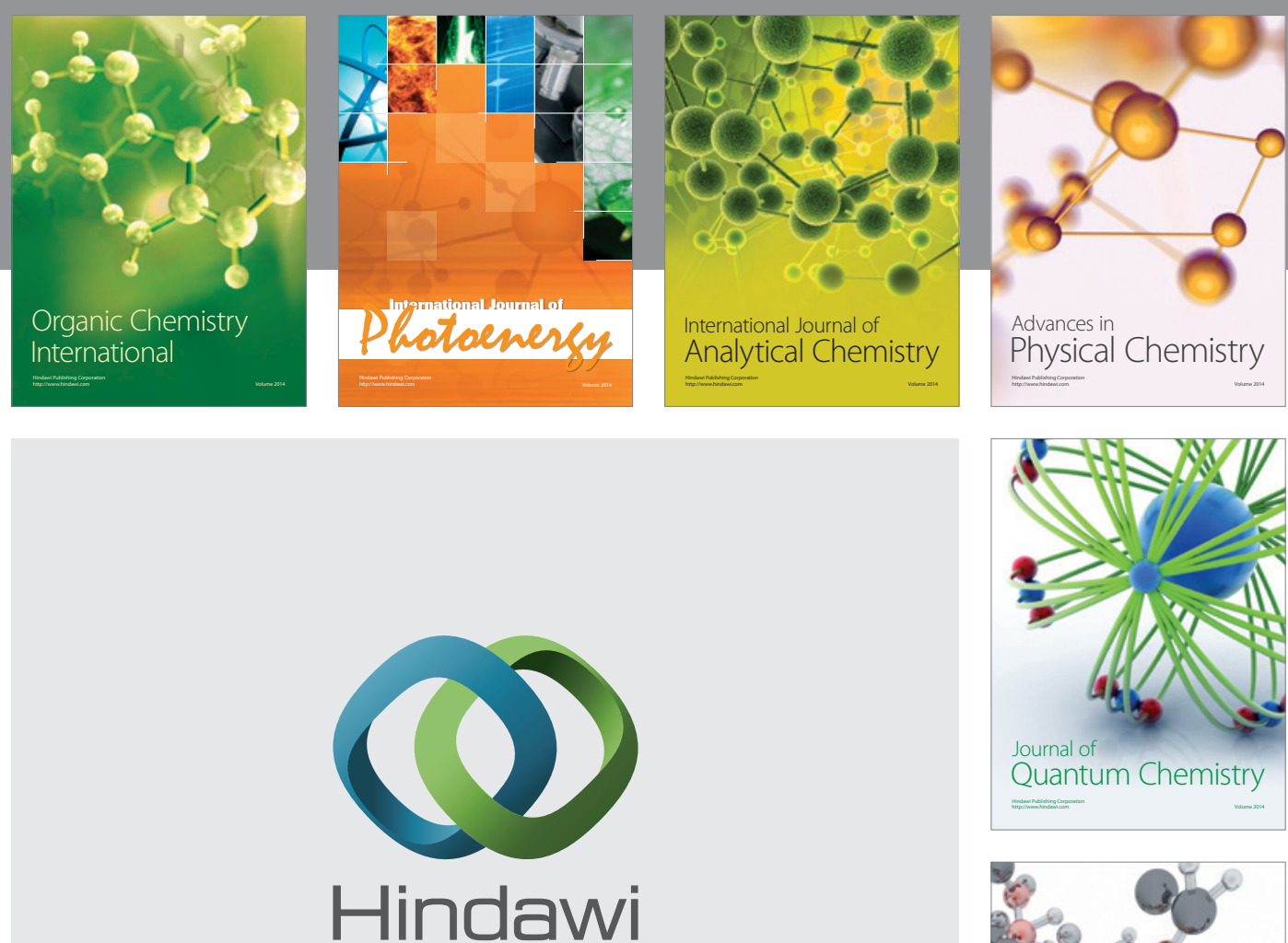

Submit your manuscripts at

http://www.hindawi.com

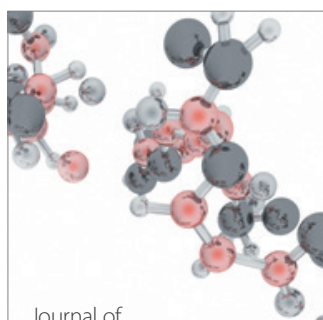

Analytical Methods

in Chemistry

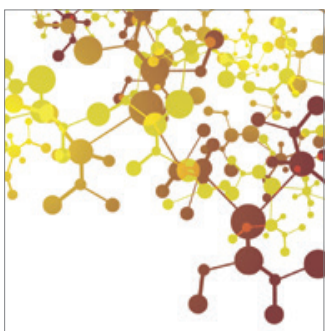

Journal of

Applied Chemistry

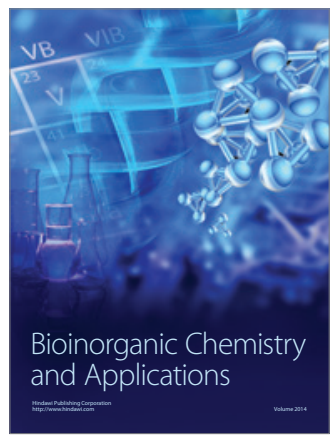

Inorganic Chemistry
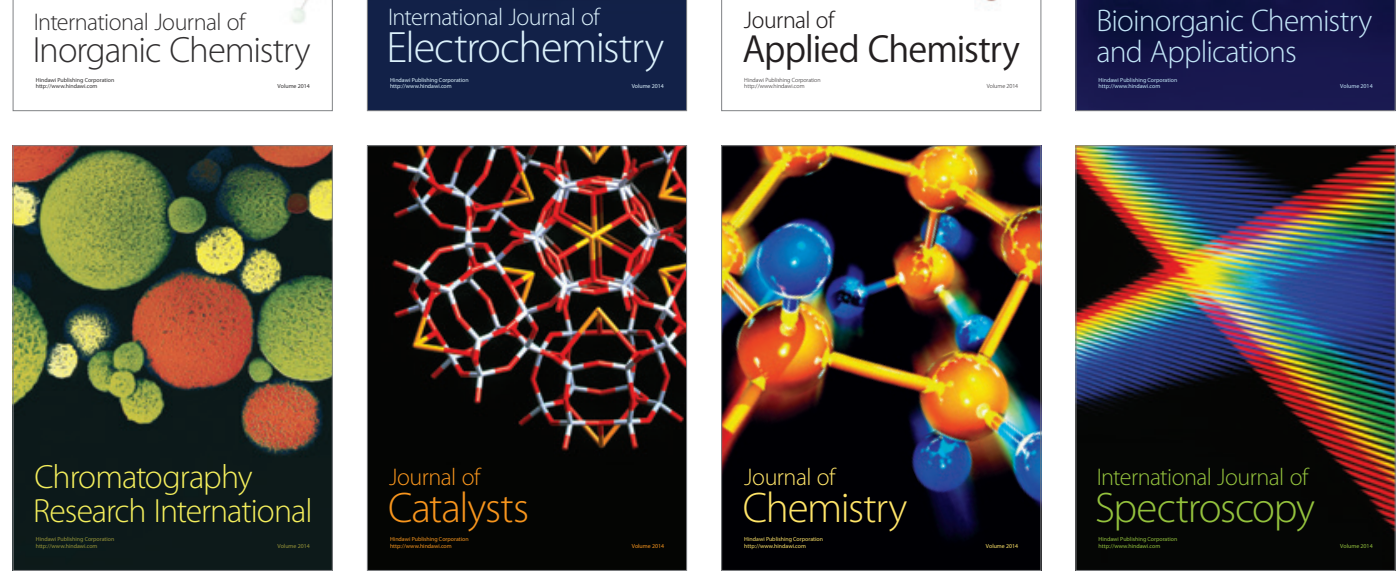